Western University

Scholarship@Western

Physical Therapy Publications

Physical Therapy School

$1-1-2010$

\title{
Description of exercise participation of adolescents with cerebral palsy across a 4-year period.
}

Laura K Brunton

Doreen J Bartlett

Follow this and additional works at: https://ir.lib.uwo.ca/ptpub

Part of the Physical Therapy Commons

Citation of this paper:

Brunton, L. K., \& Bartlett, D. J. (2010). Description of exercise participation of adolescents with cerebral palsy across a 4-year period. Pediatric Physical Therapy, 22(2), 180-187. 


\begin{abstract}
Purpose: The primary purposes were to describe: 1) the types of exercise participation of adolescents with cerebral palsy (CP), 2) the weekly duration of stretching, strengthening, and cardiovascular exercise, and 3) how the level of activity compares to national health guidelines. Methods: Participants were 126 males and 104 females (14.7, SD =1.7 years) who reported on the physical activities in the previous week using a questionnaire designed for this study. Analyses comprised frequency counts and proportions, stacked bar graphs and 2-way ANOVAs of exercise participation by GMFCS and gender.

Results: There was a significant interaction of GMFCS level and gender for stretching; females stretched more than males. A significant main effect of GMFCS level was detected for "light" and "moderate" exercise. An average of 9.4 and $11.4 \%$ of our sample participated in weekly levels of "moderate" and "vigorous" exercise, respectively.
\end{abstract}

Conclusions: Pediatric physical therapists should expend more effort on health promotion to increase exercise participation rates among youth with $\mathrm{CP}$. 


\section{Introduction and Purpose}

Physical activity (PA) is defined as 'any bodily movement produced by skeletal muscles that results in energy expenditure' (p. 126). ${ }^{1}$ PA provides numerous health benefits to persons with and without disability. ${ }^{2}$ Persons with disabilities are known to have lower PA than persons without disabilities. ${ }^{3}$ Cerebral palsy (CP) is a condition for which PA, and especially exercise, has been strongly promoted, largely to prevent associated secondary conditions. ${ }^{4-8}$ We now explore what is known about engagement in PA and exercise participation in children and youth with CP.

Children and adolescents with CP are known to have a lower level of activity than peers without disabilities. ${ }^{9,10}$ They had significantly less uptime, ${ }^{9}$ fewer daily step counts have been reported and daily walking activity decreased with functional ability. ${ }^{10}$ Similarly, young ambulatory children with $\mathrm{CP}$ were not participating in activities that provided enough intensity to reap the health benefits of PA. ${ }^{11}$ Also, activities chosen were of slower tempo compared to their peers without disabilities. ${ }^{12,13}$ Others have identified a much larger proportion of sedentary participants with CP (29\%) compared to an able-bodied comparison group (10\%). ${ }^{14}$ As well, PA scores decrease on average during the adolescent years after a peak between the ages of 10 to 12 years, and adolescents adopt a more sedentary lifestyle during their second decade. ${ }^{14}$ Studies conducted around the world ${ }^{15-19}$ have also demonstrated that adolescents with $\mathrm{CP}$ are less active than their peers. However, most of these data come from studies in which participants were not analyzed by level of motor function or were part of a larger 'disability cohort'. Maher and colleagues $^{12}$ investigated PA patterns of adolescents with CP aged 11 to 17 years. The least physically active response on a self-report measure was consistently reported and they reported lower average levels of PA compared to age-matched controls. ${ }^{12}$ They found a strong association 
between overall PA level and gross motor function, such that more PA is associated with higher levels of motor function. They also demonstrated a significant inverse relationship between PA and age. ${ }^{12}$ No significant associations were made between PA and gender; however, a trend of more male PA compared to female participation was seen. Among adolescents without disabilities, males have more physical activity compared to females for all types of activity. ${ }^{20} \mathrm{~A}$ limitation to these previous studies is the lack of investigation across all Gross Motor Function Classification System (GMFCS) levels ${ }^{21}$; the focus has been placed on GMFCS levels I, II and III $^{9,10}$ or ambulatory subjects ${ }^{11}$ in most studies except for one. ${ }^{12}$

In contrast to PA, there is little information about exercise participation and activity selection of youth with CP. Although Maher et al., ${ }^{12}$ provided ranking of selected activities, there is no published research on the types and rates of exercise participation of adolescents with $\mathrm{CP}$ across all GMFCS levels. ${ }^{22}$ This information is essential to develop a set of PA guidelines allowing physical therapists to tailor PA and exercise programs, that have an added health benefit specific to children based on their GMFCS level and gender to promote adherence to the program. Health promotion initiatives specific to youth with $\mathrm{CP}$ are needed to further encourage participation. It is also important to understand the proportion of teens with $\mathrm{CP}$ who are and who are not meeting the current recommendations set forth by national agencies such as Health Canada. $^{23}$ The current recommendations are 60 minutes of daily moderate PA and 30 minutes of daily vigorous PA.

The primary purposes of this paper are to 1) describe the types of exercise participation of adolescents with CP by gender and GMFCS level, 2) describe the weekly duration of stretching, strengthening and cardiovascular exercise and to determine effects of gender and 
GMFCS level, and 3) determine how the adolescents' level of activity compares to national health guidelines. A secondary purpose was to examine activity participation over time.

\section{Methods}

Design

The data reported here were obtained from the first and final data collection points of a 4year prospective cohort study called the Adolescent Study of Quality of Life, Mobility and Exercise (ASQME).

\section{Setting and Participants}

Participants in the ASQME were recruited from the Ontario Motor Growth (OMG) study, ${ }^{24}$ which followed a stratified random sample of 657 children with CP attending one of 19 publicly-funded children's rehabilitation centres in Ontario, Canada between 1996 and 2001. The OMG cohort is considered to be population-based because each of the centres serves the majority of children with CP in each geographical area. Stratification was based on the GMFCS level $^{21}$ and age; therefore this cohort is not necessarily representative with respect to those factors.

All OMG participants who were older than or equal to 11 years of age in April of 2002 (n $=343)$ were invited to participate in ASQME. Seventy-one percent $(n=244)$ of the youth and families agreed to participate and 230 were enrolled for the first data collection point. Participants completed the Exercise Questionnaire at each of four annual data collection points; however, only the first and fourth are used in this paper. ASQME participants did not differ from eligible OMG participants who did not take part in ASQME on all background demographic characteristics except for maternal education; ASQME participants had mothers with higher education. Overall, the ASQME sample comprised 104 girls (45.2\%) and 126 boys (54.8\%) with 
mean ages of 14.7 and $14.8(\mathrm{SD}$ for both $=1.7)$ years at the study onset. All participants were between the ages of 11 and 18 years at the beginning of the study. Table 1 contains the distribution of gender and age by GMFCS levels. The ASQME study was approved by the Research Ethics Board at McMaster University. Written informed consent was obtained from caregivers and written assent was obtained from the adolescent participants prior to data collection.

Measures

Of the many measures used in ASQME, two are relevant to this paper: the GMFCS and the Exercise Questionnaire. The GMFCS ${ }^{21}$ is a standardized, reliable and valid system to classify motor function of children with $\mathrm{CP}$ aged 2 to 12 years. A version for youth aged 12 to 18 years was validated as part of the ASQME work. ${ }^{25}$ Using this system, each individual is classified based on his or her self-initiated movement and need for assistive technology and wheeled mobility. Individuals are classified into one of five levels, from $\mathrm{V}$ in which the person has very limited mobility, to I in which the person is able to walk and run, but is limited in more advanced motor abilities. Trained and reliable therapists classified ASQME participants using the GMFCS; all therapists achieved greater than or equal to $80 \%$ agreement with a criterion.

As done in other population-based research, ${ }^{26}$ we used a questionnaire to collect data on PA in the form of exercise. We defined "exercise" as activities that involve stretching, strengthening, or physical effort. We defined activities that involve effort as being associated with the heart working harder and faster, breathing to be deeper and with the body perspiring or sweating. Following a design by Sallis and colleagues, ${ }^{27}$ we developed the Exercise Questionnaire to be completed by either the adolescent alone or the parent and adolescent together. We generated a list of activities from the Previous Day Physical Activity Record 
(PDPAR), ${ }^{28}$ an instrument that was developed for youth, but that we regarded as too complex for the sample we were studying due to the cognitive load associated with the questionnaire. We also added items that were appropriate for youth with $\mathrm{CP}$ through consultation among expert investigators involved in the study; these items were confirmed through pilot testing with youth with $\mathrm{CP}$ which supported the content validity of the questionnaire. As others have done, ${ }^{29}$ we asked each participant to read through the list of activities and then to 1) check "yes" for any activity that they had performed in the previous week, 2) indicate the number of times that they performed that activity in the previous week, 3) write down the number of minutes, on average, for each occasion, and 4) indicate the intensity of the activity, on average, from a choice of 'light', 'medium', or 'hard', based on definitions provided on the questionnaire (Appendix A). Participants either self-reported the questionnaire alone (23.6\%), with help from family members (48.2\%) or the report was completed by parental proxy (28.2\%). The results were not significantly different by method of administration for light and moderate exercise; however, was significantly different for vigorous exercise. Questionnaires completed by proxy reported less vigorous exercise compared to questionnaires completed alone or with help. The majority of questionnaires completed by proxy were for participants in GMFCS level V and so this is result is not surprising.

\section{Statistical Analyses}

The exercise data were first summarized by describing the most frequent types of exercise participation by gender and GMFCS levels. Weekly duration of exercise participation in stretching and strengthening was determined by multiplying the frequency and duration of these activities. Light, medium, and hard cardiovascular exercise participation was determined by summing the products of frequency and duration across all responses, other than stretching 
and strengthening. All weekly duration activities (in minutes) were summarized by means, standard deviations, medians and ranges by gender and GMFCS levels. A 2-way ANOVA was conducted to determine the effect of gender and GMFCS level on stretching and strengthening and on light, medium, and hard cardiovascular exercise; Tukey's test was used for post-hoc testing. To determine how the adolescents' level of activity compares to national health guidelines, the data were collapsed to establish proportions of our sample who participated in 'none', 'some' or 'the recommended amount' for moderate (our 'medium' category) or vigorous (our 'hard' category) activity. Chi-square analysis was used to determine the effect of gender and GMFCS level on categorization of participation. A t-test was conducted between the total duration of stretching and strengthening, and participation in light, moderate, and vigorous exercise between time 1 and time 4. A Chi-square analysis was done to determine if classification of 'none', 'some', and 'recommended' levels of moderate or vigorous exercise participation differed over the 4 years of the study. SPSS, version 16 was used for analysis. An alpha value of 0.05 was established for statistical significance.

\section{Results}

Table 2 contains the relative frequencies of participation in various activities by gender and GMFCS level. A wide variety of activities were reported by the adolescents in the study and only the 5 most frequent responses per level and gender are recorded.

Table 3 contains a summary of the weekly duration of participation in stretching and strengthening and in light, moderate, and vigorous cardiovascular exercise. Two-way ANOVAs yielded the following statistically significant effects. For stretching, there was a significant interaction of GMFCS level and gender $(\mathrm{F}=2.63 \mathrm{df}=4, \mathrm{p}=.04)$ and a significant main effect of GMFCS level $(\mathrm{F}=9.31, \mathrm{df}=4, \mathrm{p}<.001)$. Participants in level V had significantly longer 
stretching durations than those in all other GMFCS levels $(\mathrm{p}<.004)$. Female participants in level $\mathrm{V}$ engaged in significantly more stretching than males in level $\mathrm{V}$, accounting for the significant interaction. There was a significant main effect of GMFCS level for 'light' intensity exercise $(\mathrm{F}=2.45, \mathrm{df}=4, \mathrm{p}=.05)$, with participants in Level $\mathrm{V}$ having significantly lower levels of light exercise than those in Level I. There was a significant main effect of GMFCS level for 'moderate' intensity exercise $(\mathrm{F}=3.26, \mathrm{df}=4, \mathrm{p}=.01)$ with participants in levels IV $(\mathrm{p}=.04)$ and $\mathrm{V}(\mathrm{p}=.05)$ having significantly less moderate exercise than those in level III. There were no significant effects for strengthening and 'vigorous' exercise.

Figures 1 and 2 contain the proportion of the sample who participated in "none" as characterized by 0 reported minutes, "some" reported minutes between 1-419 for moderate PA and 1-209 minutes for vigorous PA, or the "recommended" amount, 420 or more minutes for moderate PA, and 210 or more minutes for vigorous PA. Health Canada's recommendations for moderate activity are being met by approximately $14 \%$ of males and $3 \%$ of females in level I, $11 \%$ of males and $14 \%$ of females in level II, $25 \%$ of males and $12.5 \%$ of females in level III, $3 \%$ of males and $0 \%$ females in level IV, and $0 \%$ of males and $5 \%$ of females in level V. Overall $9.5 \%$ of males and $6.5 \%$ of females met the current recommendations for moderate activity. In terms of vigorous activity $21 \%$ of males and $15 \%$ of females in Level I, $13 \%$ of males and $5 \%$ of females in level II, and $19 \%$ of males and $0 \%$ females in level III, $6 \%$ of males and $10 \%$ of females in level IV and $0 \%$ of males and $5 \%$ of females in level V are meeting the recommendations set forth by Health Canada. Overall $11.7 \%$ of males and $7.8 \%$ of females are meeting the recommendations for vigorous exercise.

The Chi-square analysis of the effect of gender on classification into 'none', 'some', or 'recommended' was non-significant for both moderate and vigorous exercise. Similar analysis 
testing the effect of GMFCS level was significant for moderate (Chi-square $=27.2, \mathrm{df} 8, \mathrm{p}=$ .001 ), but not vigorous exercise. Participants in Levels IV and V were less likely to engage in moderate activity than those in levels I to III.

T-tests of the total duration of stretching, strengthening, and 'vigorous' exercise were non-significantly different between time 1 and time 4 . Significant differences were obtained for 'light' and 'moderate' exercise $(\mathrm{t}=2.37, \mathrm{df}=393, \mathrm{p}=.02 ; \mathrm{t}=2.78, \mathrm{df}=353, \mathrm{p}=.006)$ with mean reductions of 31 and 72 minutes per week, respectively. The Chi-Square test of the difference in classification of 'none', 'some', or 'recommended' was significant for both 'moderate' and 'vigorous' exercise (Chi-square $=15.3, \mathrm{df}=8, \mathrm{p}=.05$; Chi-square $=15.7, \mathrm{df}=8$, $p=0.5$ ) with a shift from the higher categories to 'none' over the four-year period. By time 4 , 68 and $84 \%$ of participants took part in no moderate or vigorous PA; this effect was largely independent of GMFCS level.

\section{Discussion and Conclusion}

This report provides the first published information on rates of exercise participation among adolescents with CP across all GMFCS levels. In our study, males did not exhibit more exercise participation than females; however, participants with more gross motor function, regardless of gender, did report greater exercise participation than those with less motor function. Consistent with previous research on PA, exercise participation decreased over the four-year period of the study. Overall, the participation rates were low. Of concern, these results may reflect an over-estimation of exercise participation due to the use of a self-report measure and social desirability bias or recall bias.

To assist with interpretation of the results with respect to type of exercise participation, we rely on the work of Maher et al. ${ }^{12}$ In their study, swimming was more highly ranked for 
adolescents with $\mathrm{CP}$ than for those without. In our study, swimming ranked in the top three activities in all categories except for females in levels III and V. Maher et al., ${ }^{12}$ reported that activities such as basketball, dancing and riding a bike were more highly ranked by adolescents without CP. Some participants in each GMFCS level and gender category (except for females in level V) in our study participated in these activities. Walking was the most frequent activity of participants in GMFCS levels I, II and III, and second most frequent among those in level IV; it was also the second most highly ranked activity in the study by Maher et al. ${ }^{12}$ In our study, participants identified the following activities that are not reported by Maher et al. ${ }^{12}$ : hockey (usually sledge hockey), baseball/catch, wheeling, bowling, and volleyball. Also other activities of lower frequency, such as martial arts and soccer, were reported in our study; a full list of the reported activities can be obtained from the corresponding author. Although it is difficult to compare these patterns of exercise participation with other studies, it is possible that at least some adolescents participated in higher intensities than in the study by Maher et al. ${ }^{12}$ Pediatric physical therapists should use this information in PA and exercise prescription to help determine the types of sports or activities that interest youth with $\mathrm{CP}$. This also may promote adherence to such programs, because if the activity is interesting and stimulating the youth may be more inclined to continue their participation over time, through adulthood. Of concern in our study is the relatively isolated nature of the activities engaged in by only a small proportion of female participants in level $\mathrm{V}$ as can be seen in Table 2. The activities reported by these participants are not of the same intensity as the activities reported for males of the same GMFCS level, and fewer people reported any activity compared to other severity levels. This is of concern due to the secondary impairments associated with this GMFCS level, such as deficits in force production, that could be relieved through participation in PA or exercise. 
The significant main effect of GMFCS level on stretching may be related to the role that stretching might play in helping to preserve range of motion (ROM) and delay or avoid the need for surgical interventions. ${ }^{30}$ An inverse relationship between stretching and function emerged. Formal stretching programs were reported more by participants with higher levels of impairment; this may be due to the emphasis on stretching in physical therapy sessions to delay surgery; it may also be possible that some activities reported by participants include minimal stretching components within the exercise. Overall, the reported levels of stretching were lower than expected; maintaining ROM and increasing muscle extensibility could benefit all adolescents with CP regardless of the level of impairment, although this assumption is controversial. ${ }^{30}$ More than half the participants performed no strengthening exercise across all GMFCS levels and both genders. This is especially troubling because individuals with $\mathrm{CP}$ have primary and secondary deficits in force production, which can lead to furthering deconditioning. ${ }^{6}$ As recommended by Damiano, ${ }^{4}$ individuals with $\mathrm{CP}$ need to be encouraged to participate in PA, including strengthening. Aside from producing increases in strength, ${ }^{31}$ isotonic strength training has been shown to promote functional gains that can be maintained even without further training ${ }^{32}$ and strength training in youth may prevent deterioration of health status. ${ }^{32}$ Strength training also has the potential to improve gait function. ${ }^{31}$

Cardiovascular exercise participation rates were low for both moderate and vigorous exercise, particularly in levels IV and V. Children with CP are known to display low levels of cardiorespiratory fitness based on reduced peak $\mathrm{VO}_{2}$ and higher submaximal energy demand of walking ${ }^{33-34}$ as well as displaying excessive energy expenditure for set walking speeds. ${ }^{6,34-37}$ It is also troubling that there was a drop in participation in both moderate and vigorous PA over the 4-year period of the study. To our knowledge no other study has identified a decline in PA 
participation of adolescents with CP over time. This is particularly problematic as levels of activity exhibited between the ages of 9 to 18 years can significantly predict the level of PA engaged in during the adult years. ${ }^{10}$ If this low level of activity in the adolescent years persists into adulthood it could lead to further secondary impairments and chronic health conditions associated with inactivity.

Of note, a large proportion of the adolescents from both genders are doing some activity, but not enough to meet Health Canada's guidelines. Perhaps there is the opportunity to increase participation with the right programming initiatives and directed health promotion efforts. Campbell ${ }^{38}$ has demonstrated a need for research on how to interrupt the cycle of increasing disability and deconditioning that is associated with chronic health conditions, as well as promoting PA practices and programs that require children and youth to take responsibility for their own personal health and fitness prior to the transition out of pediatric care.

In addition to possible inflated estimates of the previous week's exercise participation levels, a second limitation of the study is a lack of definitive information about the reliability of our Exercise Questionnaire. Three attempts were made over three years to determine test-retest reliability. First, 300 flyers were distributed to children and youth with disabilities in the Thames Valley District School Board. Four youth agreed to participate; one had CP. Second, 189 letters of invitation were distributed to children and youth with disabilities receiving services through the Thames Valley Children's Centre. Five youth agreed to participate, 2 had CP. Finally, attempts were made to obtain second estimates of exercise participation by asking participants in the ASQME study; six responses were received. This total data set from nine participants yielded a low intraclass correlation coefficient, primarily due to lack of variability in the data (ie. exercise participation was low). Nonetheless, there was no significant difference between test- 
retest scores. The difficulty in obtaining a sample to examine test-retest reliability is interpreted as another indicator that adolescents with $\mathrm{CP}$ are not interested in PA and exercise. Nonetheless, evidence from the 7-Day Physical Activity Recall and the Godin-Shephard Questionnaire, as indicated by Pearsons' correlations coefficients of 0.77 and 0.81 respectively, suggest that children and youth developing typically, who are older than grade five, are able to report on participation in PA for the previous week. ${ }^{39}$

Our work suggests that future work should focus on determining barriers and facilitators to PA in adolescents with $\mathrm{CP}$ as well as investigating strategies to promote PA and engagement in exercise of sufficient frequency, duration, and intensity to yield health benefits. A particular emphasis needs to be made to ensure that adequate PA levels are continued into adulthood. In conclusion, the lower than acceptable and declining exercise participation in adolescents with $\mathrm{CP}$ that were observed in this study clearly indicate that renewed and sustained efforts to promote PA and exercise participation are required. 


\section{References}

1. Caspersen CJ, Powell KE, Christenson GM. Physical activity, exercise and physical fitness: Definitions and distinctions for health-related research. Public Health Rep. 1985;100:126131.

2. Sothern MS, Loftin M, Suskind RM, Udall JN, Blecker U. The health benefits of physical activity in children and adolescents: Implications for chronic disease prevention. Eur $J$ Pediatr. 1999;158:271-274.

3. Statistics Canada. Participation and Activity Limitation Survey. Statistics Canada, Ottawa, Ont. 2001.

4. Damiano, DL. Activity, Activity, Activity: Rethinking our physical therapy approach to cerebral palsy. Phys Ther. 2006;86;1534-1540.

5. Fowler EG, Kolobe THA, Damiano DL, Thorpe DE, Morgan DW, Brunstrom JE, Coster WJ, Henderson RC, Pitetti KH, Rimmer JH, Rose J, Stevenson RD. Promotion of physical fitness and prevention of secondary conditions for children with cerebral palsy: Section on pediatrics research summit proceedings. Phys Ther. 2007;87:1495-1510.

6. Durstine JL, Painter P, Franklin BA, Morgan D, Pitetti KH, Roberts SO. Physical activity for the chronically ill and disabled. Sports Med. 2000;30:207-219.

7. Dodd KJ, Taylor NF, Damiano DL. A systematic review of the effectiveness of strengthtraining programs from people with cerebral palsy. Arch Phys Med Rehabil. 2002;83:11571164.

8. Verschuren O, Ketelaar M, Takken T, Helders PJM, Gorter JW. Exercise programs for children with cerebral palsy: A systematic review of the literature. Am J Phys Med Rehabil. 2008;87:404-417. 
9. Pirpiris M, Graham HK. Uptime in children with cerebral palsy. J Pediatr Orthop. 2004;24:521-528.

10. Bjornson KF, Belza B, Kartin D, Logsdon R, McLaughlin JF. Ambulatory physical activity performance in youth with cerebral palsy and youth who are typically developing. Phys Ther. 2007;87:248-257.

11. van den Berg-Emons EJG, Sarls WHM, de Barbanson DC, Westerterp KR, Huson A, van Baak MA. Daily physical activity of schoolchildren with spastic diplegia and of healthy control subjects. J Pediatr. 1995;127:578-584.

12. Maher CA, Williams MT, Olds T, Lane AE. Physical and sedentary activity in adolescents with cerebral palsy. Dev Med Child Neurol. 2007;49:450-457.

13. Brown M, Gordon WA. Impact of impairment on activity patterns of children. Arch Phys Med Rehabil. 1987;68:828-832.

14. Longmuir PE, Bar-Or O. Physical activity of children and adolescents with a disability: Methodology and effects of age and gender. Pediatr Exerc Sci. 1994;6:168-177.

15. Stallings VA, Zemel BS, Davies JC, Cronk CE, Charney EB. Energy Expenditure of children and adolescents with severe disabilities: a cerebral palsy model. Am J Clin Nutr. 1996;64:627-634.

16. Bandini LG, Schoeller DA, Fukagawa NK, Wykes LJ, Dietz WH. Body composition and energy expenditure in adolescents with cerebral palsy or myelodysplasia. Pediatr Res. 1991;29:70-77.

17. Margalit M. Leisure activities of cerebral palsied children. Isr J Psychiartry Relat Sci. $1981 ; 18: 209-214$. 
18. Maltais DB, Pierrynowski MR, Galea VA, Matsuzaka A, Bar-Or O. Habitual physical activity levels are associated with biomechanical walking economy in children with cerebral palsy. Am J Phys Med Rehabil. 2005;84:36-45.

19. Longmuir PE, Bar-Or O. Factors influencing the physical activity levels of youths with physical and sensory disabilities. Adapt Phys Act Q. 2000;17:40-53.

20. Caspersen CJ, Pereira MA, Curran KM. Changes in physical activity patterns in the United States, by sex and cross-sectional age. Med Sci Sports Exerc. 2000;32:1601-1609.

21. Palisano R, Rosenbaum P, Walter S, Russell D, Wood E, Galuppi B. Development and reliability of a system to classify gross motor function in children with cerebral palsy. Dev Med Child Neurol. 1997;39:214-23.

22. Rimmer JH. Health promotion for people with disabilities: The emerging paradigm shift from disability prevention to prevention of secondary conditions. Phys Ther. 1999;79:495502.

23. http://www.phac-aspc.gc.ca/pau-uap/paguide/child_youth/index.html- Accessed August 31st 2008

24. Rosenbaum PL, Walter SD, Hanna SE, Palisano RJ, Russell DJ, Raina P, Wood E, Bartlett DJ, Galuppi B. Prognosis for gross motor function in cerebral palsy: Creation of motor development curves. JAMA. 2002;288:1357-1363.

25. Palisano RJ, Rosenbaum P, Bartlett D, Livingston MH. Content validity of the Expanded and Revised Gross Motor Function Classification System. Dev Med Child Neurol. 2008;50;744750.

26. Halfmann PL, Keller C, Allison M. Pragmatic assessment of physical activity. Nurse Pract Forum. 1997;8:160-165. 
27. Sallis JF, Haskell WL, Wood PD, Fortmann SP, Rogers T, Blair SN, Paffenbarger RS. Physical activity assessment methodology in the Five-City Project. Am J Epidemiol. 1985;121:91-106.

28. Weston AT, Petosa R, Pate RR. Validation of an instrument for measurement of physical activity in youth. Med Sci Sports Exerc. 1997;29:138-143.

29. Cartmel B, Moon TE. Comparison of two physical activity questionnaires, with a diary, for assessing physical activity in an elderly population. J Clin Epidemiol. 1992;45:877-883.

30. Wiart L, Darrah J, Kembhavi G. Stretching with children with cerebral palsy: What do we know and where are we going? Pediatr Phys Ther. 2008;20:173-178.

31. Eek MN, Tranberg R, Zügner R, Alkema K, Beckung E. Muscle strength training to improve gait function in children with cerebral palsy. Dev Med Child Neurol. 2008;50:759-764.

32. Mockford M, Caulton J. Systematic review of progressive strength training in children and adolescents with cerebral palsy who are ambulatory. Pediatr Phys Ther. 2008;20:318-333.

33. Hoofwijk M, Unnithan V, Bar-Or O. Maximal treadmill performance in children with cerebral palsy. Pediatr Exerc Sci. 1995;7:305-313.

34. Unnithan VB, Dowling JJ, Frost G, Bar-Or O. Role of co-contraction in the $\mathrm{O}_{2}$ cost of walking in children with cerebral palsy. Med Sci Sports Exerc. 1996;28:1498-1504.

35. Campbell J, Ball J. Energetics of walking in cerebral palsy. Orthop Clin North Am. 1978;9:374-377.

36. Rose J, Gamble JG, Medeiros J, Burgos A, Haskell WL. Energy cost of walking in normal children and in those with cerebral palsy: comparison of heart rate and oxygen uptake. $J$ Pediatr Orthop. 1989;9:276-279. 
37. Norman JF, Bossman S, Gardner P, Moen C. Comparison of energy expenditure index and oxygen consumption index during self-paced walking in children with spastic diplegia cerebral palsy and children without physical disabilities. Pediatr Phys Ther. 2004;46:206211.

38. Campbell SK. Therapy programs for children that last a lifetime. Phys Occup Ther Pediatr. $1997 ; 17: 1-15$.

39. Sallis JF, Buono MJ, Roby JJ, Micale FG, Nelson JA. Seven-day recall and other physical activity self-reports in children and adolescents. Med Sci Sport Exerc. 1993;25:99-108. 
Table 1. Description of the Gender and Age Distribution of Participants at the study outset

\begin{tabular}{|ll|l|l|}
\hline \multicolumn{2}{|l|}{ GMFCS Level } & Females & Males \\
\hline I & number (proportion) & $27(26.0 \%)$ & $35(27.8 \%)$ \\
mean age (SD) & $15.0(1.8)$ & $14.8(1.8)$ \\
\hline II & number (proportion) & $22(21.2 \%)$ & $17(13.5 \%)$ \\
& mean age (SD) & $14.9(1.7)$ & $14.8(1.8)$ \\
\hline III & number (proportion) & $16(15.4 \%)$ & $17(13.5 \%)$ \\
& mean age (SD) & $14.5(1.7)$ & $14.9(1.7)$ \\
\hline IV & number (proportion) & $21(20.1 \%)$ & $33(26.2 \%)$ \\
& mean age (SD) & $15.0(1.8)$ & $14.5(1.7)$ \\
\hline V & number (proportion) & $18(17.3 \%)$ & $24(19.0 \%)$ \\
& mean age (SD) & $13.8(1.5)$ & $15.1(1.6)$ \\
\hline Total N & 104 & 126 \\
Mean Age (SD) & $14.7(1.7)$ & $14.8(1.7)$ \\
\hline
\end{tabular}


Table 2 - Most Frequent Activities Reported by Participants at the first data collection point

\begin{tabular}{|c|c|c|c|c|}
\hline GMFCS Level & \multicolumn{2}{|c|}{ Males } & \multicolumn{2}{|c|}{ Females } \\
\hline 1 & $\begin{array}{l}\text { Activity } \\
\text { Walking } \\
\text { Swimming } \\
\text { Basketball } \\
\text { Biking } \\
\text { Dance }\end{array}$ & $\begin{array}{l}\text { Number (\%) } \\
19(54 \%) \\
18(51 \% \\
16(46 \%) \\
13(37 \%) \\
7(20 \%)\end{array}$ & $\begin{array}{l}\text { Activity } \\
\text { Walking } \\
\text { Dance } \\
\text { Swimming } \\
\text { Biking } \\
\text { Basketball }\end{array}$ & $\begin{array}{l}\text { Number (\%) } \\
17(63 \%) \\
16(59 \%) \\
9(33 \%) \\
5(19 \%) \\
4(15 \%)\end{array}$ \\
\hline II & $\begin{array}{l}\text { Activity } \\
\text { Walking } \\
\text { Swimming } \\
\text { Dance } \\
\text { Wheeling } \\
\text { Hockey }\end{array}$ & $\begin{array}{l}\text { Number (\%) } \\
11(65 \%) \\
9(53 \%) \\
6(35 \%) \\
3(18 \%) \\
3(18 \%)\end{array}$ & $\begin{array}{l}\text { Activity } \\
\text { Walking } \\
\text { Swimming } \\
\text { Dance } \\
\text { Volleyball } \\
\text { Bowling }\end{array}$ & $\begin{array}{l}\text { Number (\%) } \\
11(50 \%) \\
7(32 \%) \\
6(27 \%) \\
3(14 \%) \\
314 \%)\end{array}$ \\
\hline III & $\begin{array}{l}\text { Activity } \\
\text { Walking } \\
\text { Hockey } \\
\text { Swimming } \\
\text { Basketball } \\
\text { Dance }\end{array}$ & $\begin{array}{l}\text { Number (\%) } \\
7(41 \%) \\
6(35 \%) \\
5(29 \%) \\
4(24 \%) \\
3(18 \%)\end{array}$ & $\begin{array}{l}\text { Activity } \\
\text { Walking } \\
\text { Wheeling } \\
\text { Dance } \\
\text { Basketball } \\
\text { Hockey }\end{array}$ & $\begin{array}{l}\text { Number (\%) } \\
8(50 \%) \\
5(31 \%) \\
4(25 \%) \\
3(19 \%) \\
2(13 \%)\end{array}$ \\
\hline IV & $\begin{array}{l}\text { Activity } \\
\text { Swimming } \\
\text { Walking } \\
\text { Baseball/Catch } \\
\text { Wheeling } \\
\text { Basketball }\end{array}$ & $\begin{array}{l}\text { Number (\%) } \\
12(36 \%) \\
11(33 \%) \\
5(15 \%) \\
4(12 \%) \\
4(12 \%)\end{array}$ & $\begin{array}{l}\text { Activity } \\
\text { Swimming } \\
\text { Walking } \\
\text { Wheeling } \\
\text { Dance } \\
\text { Basketball }\end{array}$ & $\begin{array}{l}\text { Number (\%) } \\
7(33 \%) \\
3(14 \%) \\
3(14 \%) \\
3(14 \%) \\
2(10 \%)\end{array}$ \\
\hline
\end{tabular}




\begin{tabular}{|l|ll|ll|}
\hline V & Activity & Number (\%) & Activity & Number (\%) \\
Swimming & $6(25 \%)$ & Gym Class & $2(11 \%)$ \\
Wheeling & $3(13 \%)$ & Boccia Ball & $2(11 \%)$ \\
Dance & $3(13 \%)$ & Bowling & $1(6 \%)$ \\
Walking & $2(8 \%)$ & Horseback Riding & $1(6 \%)$ \\
& Baseball/Catch & $2(8 \%)$ & Fitness & $1(6 \%)$ \\
\hline
\end{tabular}


Table 3. Weekly duration of exercise participation, in minutes, by gender and GMFCS levels [mean (SD) top row; median (range) below).

\begin{tabular}{|c|c|c|c|c|c|c|c|c|c|c|}
\hline \multirow[t]{2}{*}{ Activity } & \multicolumn{2}{|c|}{ Level I } & \multicolumn{2}{|c|}{ Level II } & \multicolumn{2}{|c|}{ Level III } & \multicolumn{2}{|c|}{ Level IV } & \multicolumn{2}{|c|}{ Level V } \\
\hline & Females & Males & Females & Males & Females & Males & Females & Males & Females & Males \\
\hline Stretching & $\begin{array}{l}8.4(16) \\
0(0-60)\end{array}$ & $\begin{array}{l}15.2(35) \\
0(0-175)\end{array}$ & $\begin{array}{l}33.6(62) \\
0(0-240)\end{array}$ & $\begin{array}{l}35.9(104) \\
0(0-420)\end{array}$ & $\begin{array}{l}53.8(84) \\
0(0-280)\end{array}$ & $\begin{array}{r}74(108) \\
20(0-360)\end{array}$ & $\begin{array}{l}46.1(57) \\
22.5(0- \\
200)\end{array}$ & $\begin{array}{l}48.9(82) \\
0(0-380)\end{array}$ & $\begin{array}{r}199.7(264) \\
90(0- \\
980)\end{array}$ & $\begin{array}{l}85(123.5) \\
10(0-420)\end{array}$ \\
\hline Strengthening & $\begin{array}{l}12.1(31) \\
0(0-120)\end{array}$ & $\begin{array}{l}15.1(41) \\
0(0-180)\end{array}$ & 0 & $\begin{array}{r}9.7(16.6) \\
0(0-50)\end{array}$ & 0 & $\begin{array}{r}8(21) \\
0(0-60)\end{array}$ & $\begin{array}{l}11.8(50) \\
0(0-212)\end{array}$ & $\begin{array}{l}3.4(16) \\
0(0-90)\end{array}$ & $\begin{array}{r}2.4(8) \\
0(0-30)\end{array}$ & $\begin{array}{r}20(98) \\
0(0-480)\end{array}$ \\
\hline $\begin{array}{l}\text { 'light' CV } \\
\text { exercise }\end{array}$ & $\begin{array}{r}140.5 \\
(248) \\
30(0-840)\end{array}$ & $\begin{array}{r}82.5(122) \\
27.5(0- \\
435)\end{array}$ & $\begin{array}{l}50.9(86) \\
2(0-300)\end{array}$ & $\begin{array}{r}50.9(116) \\
3(0- \\
470)\end{array}$ & $\begin{array}{r}141.9 \\
(248) \\
45(0-846)\end{array}$ & $\begin{array}{r}58(75) \\
0(0-210)\end{array}$ & $\begin{array}{l}34.2(78) \\
0(0-325)\end{array}$ & $\begin{array}{l}84(243) \\
0(0-980)\end{array}$ & $\begin{array}{l}25(42.4) \\
0(0-130)\end{array}$ & $\begin{array}{l}20.8(47) \\
0(0-150)\end{array}$ \\
\hline $\begin{array}{l}\text { 'moderate CV } \\
\text { exercise }\end{array}$ & $\begin{array}{l}119.4 \\
(240) \\
60(0- \\
1210)\end{array}$ & $\begin{array}{l}193.1 \\
(309) \\
50(0- \\
1190)\end{array}$ & $\begin{array}{l}287.8 \\
(529) \\
60(0- \\
1830)\end{array}$ & $\begin{array}{l}200.3 \\
(408) \\
75(0- \\
1635)\end{array}$ & $\begin{array}{r}185.8 \\
(433) \\
42.5(0- \\
1750)\end{array}$ & $\begin{array}{l}388.3 \\
(713) \\
90(0- \\
2630)\end{array}$ & $\begin{array}{r}21.7(45) \\
0(0- \\
150)\end{array}$ & $\begin{array}{r}84.5(185) \\
0(0-960)\end{array}$ & $\begin{array}{l}115(196) \\
0(0-780)\end{array}$ & $\begin{array}{l}24.2(53) \\
0(0-210)\end{array}$ \\
\hline
\end{tabular}




\begin{tabular}{|c|c|c|c|c|c|c|c|c|c|c|}
\hline 'vigorous CV & $97.7(211)$ & $128(244)$ & $35.6(91)$ & $79.8(170)$ & $23.8(44)$ & $119(247)$ & $72.5(117)$ & $55.2(187)$ & $28.8(74)$ & $10.2(22)$ \\
\hline exercise & $0(715)$ & $0(0-1110)$ & $0(0-360)$ & $0(0-645)$ & $0(0-140)$ & $0(0-930)$ & $0(0-415)$ & $0(0-1030)$ & $0(0-280)$ & $0(0-60)$ \\
\hline
\end{tabular}

Note: CV - Cardiovascular 
Figure Legends

Figure 1. Proportion of sample participating in moderate exercise by gender and GMFCS level (Inactive $=0$ minutes, Some Activity = 1-419 minutes, Meeting Recommendations $=420$ or more minutes per week)

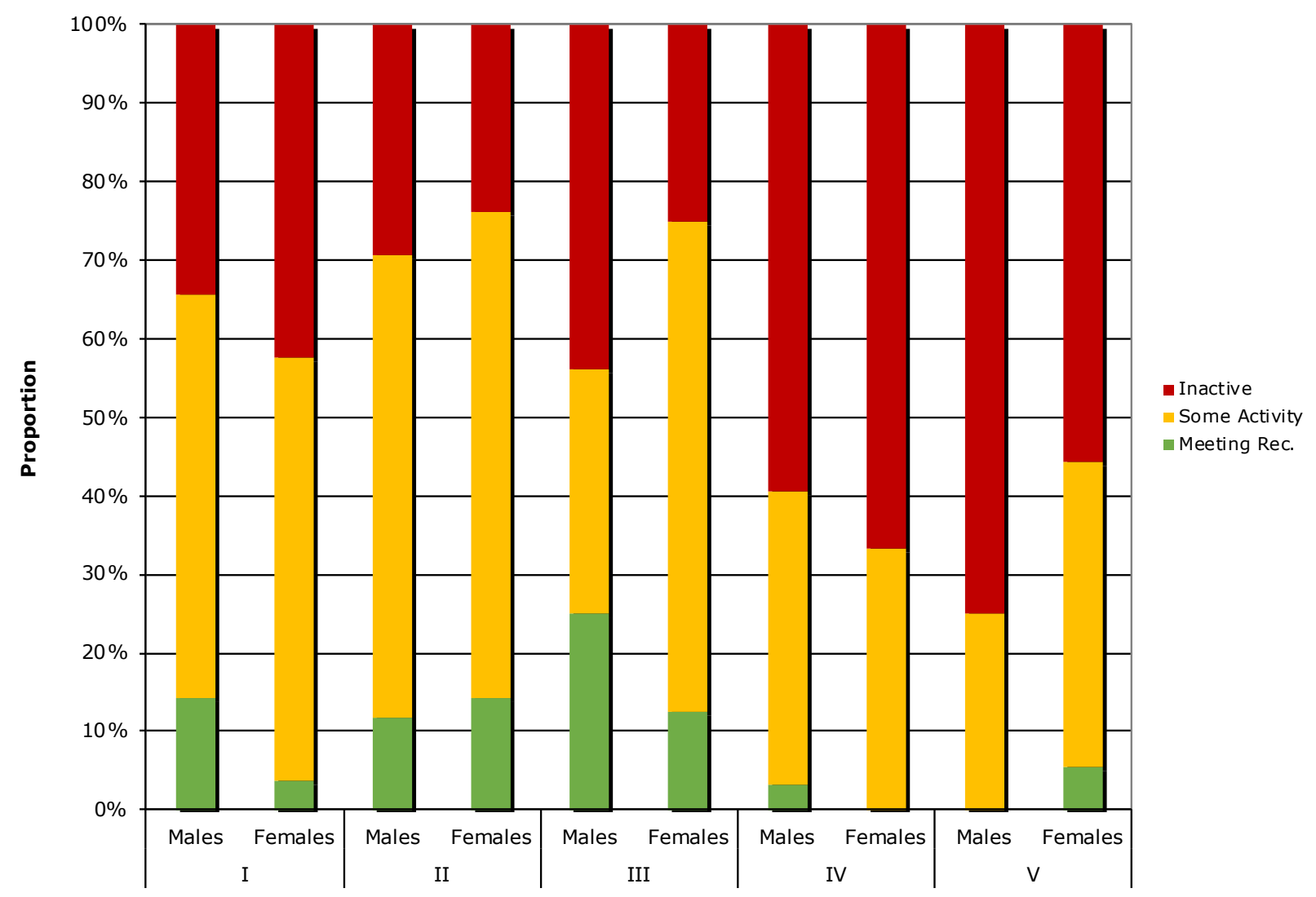


Figure 2. Proportion of sample participating in vigorous exercise by gender and GMFCS level (Inactive $=0$ minutes, Some Activity = 1-209 minutes, Meeting Recommendations $=210$ or more minutes per week)

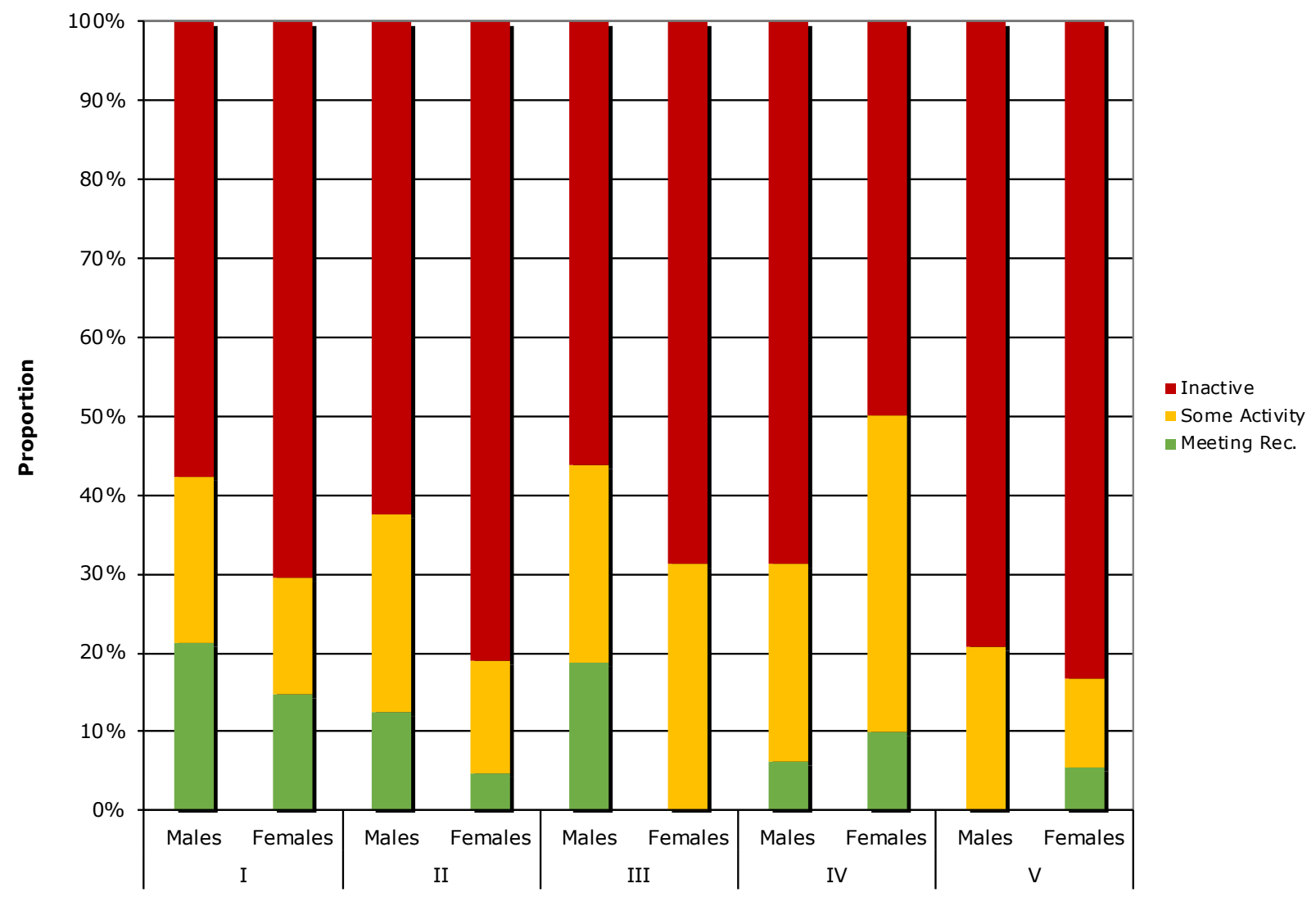


Appendix A

\section{Exercise Questionnaire}

The chart on the next page asks about the exercises you did last week. By "exercise", we mean activities that involve stretching, strengthening, or physical effort. Activities that involve effort or exertion cause the following things: 1) the heart works harder and faster, 2) breathing is deeper, and 3) the body perspires or sweats.

The $1^{\text {st }}$ column in the chart asks you to think about and circle the number for the exercises you did over the past week. There is some space for you to write in the other "sports", or "exercises" that you did.

The $2^{\text {nd }}$ column in the chart asks you to write-in the number of different times in the past week you did each of the exercises listed. If you didn't do an exercise at all, just leave the space blank.

The $3^{\text {rd }}$ column in the chart asks you to write-in the average amount of time (in minutes) you spent doing each of the exercises listed, each time. You won't need to put anything in this column for the exercises you did not do at all last week.

The $4^{\text {th }}$ column in the chart asks you to write-in how hard you worked on average when you did each exercise last week. Again, you won't need to put anything in this column for the exercises you did not do at all last week.

When you are thinking about how hard you worked, please choose either light, medium, or hard according to the descriptions below:

$\begin{array}{ll}\text { Light } & \text { normal heart rate and breathing, no sweating } \\ \text { Medium } & \text { some increase in heart rate and breathing } \\ \text { Hard } & \text { heart working hard, breathing very deep, sweating }\end{array}$




\section{Exercise Questionnaire}

Name:

Study ID:

Date of Birth:

Date Completed:

Completed by: Study participant independently [ ] or with caregiver assistance [ ]

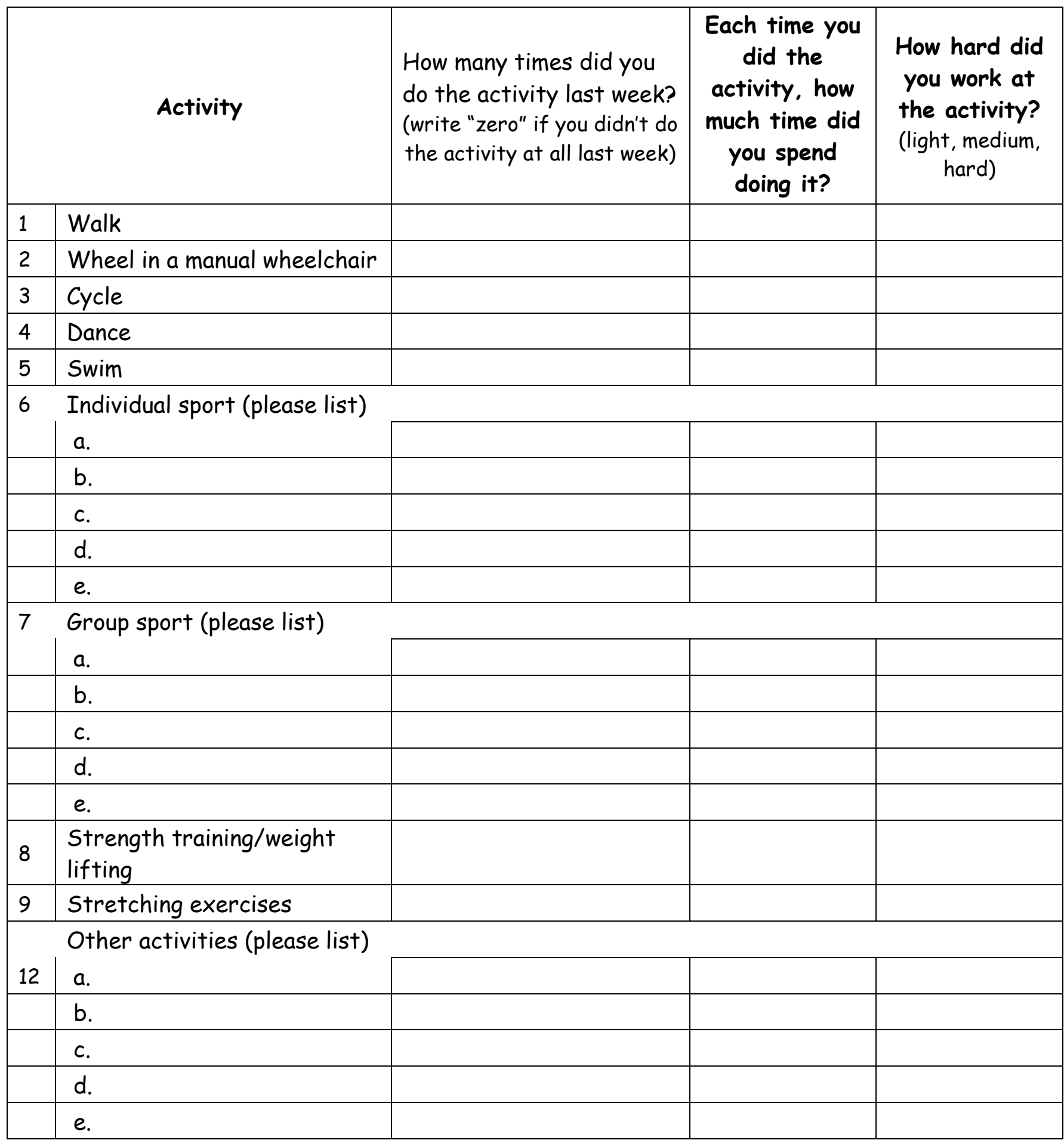


Light normal heart rate and breathing, not sweating

Medium some increase in heart rate and breathing

Hard heart working hard, breathing very deep, sweating 